This article was downloaded by:[Swets Content Distribution]

On: 19 July 2007

[Swets Content Distribution]

Access Details: [subscription number 768307933]

Publisher: Psychology Press

Informa Ltd Registered in England and Wales Registered Number: 1072954

Registered office: Mortimer House, 37-41 Mortimer Street, London W1T 3JH, UK

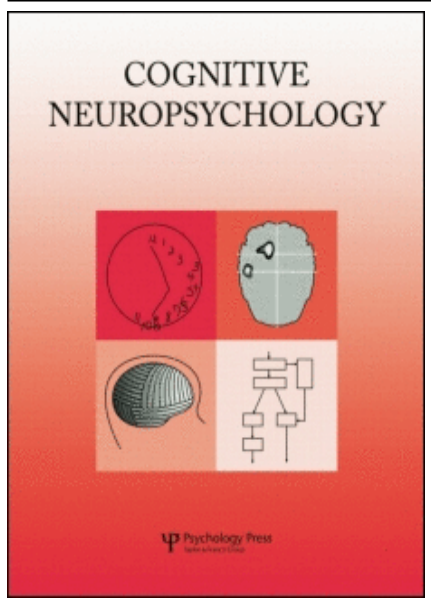

\title{
Cognitive Neuropsychology
}

Publication details, including instructions for authors and subscription information: http://www.informaworld.com/smpp/title content=t713659042

\section{"Patterns of Paralexia" Revisited: Report of a Case of} Visual Dyslexia

Matthew A. Lambon Ralph Andrew; W. Ellis

Online Publication Date: 01 October 1997

To cite this Article: Andrew, Matthew A. Lambon Ralph and Ellis, W. , (1997)

'"Patterns of Paralexia" Revisited: Report of a Case of Visual Dyslexia', Cognitive

Neuropsychology, 14:7, $953-974$

To link to this article: DOI: $10.1080 / 026432997381312$

URL: http://dx.doi.org/10.1080/026432997381312

\section{PLEASE SCROLL DOWN FOR ARTICLE}

Full terms and conditions of use: http://www.informaworld.com/terms-and-conditions-of-access.pdf

This article maybe used for research, teaching and private study purposes. Any substantial or systematic reproduction, re-distribution, re-selling, loan or sub-licensing, systematic supply or distribution in any form to anyone is expressly forbidden.

The publisher does not give any warranty express or implied or make any representation that the contents will be complete or accurate or up to date. The accuracy of any instructions, formulae and drug doses should be independently verified with primary sources. The publisher shall not be liable for any loss, actions, claims, proceedings, demand or costs or damages whatsoever or howsoever caused arising directly or indirectly in connection with or arising out of the use of this material.

(C) Taylor and Francis 2007 


\title{
"Patterns of Paralexia" Revisited: Report of a Case of Visual Dyslexia
}

\author{
Matthew A. Lambon Ralph \\ MRC Applied Psychology Unit, Cambridge, UK \\ Andrew W. Ellis \\ University of York, UK
}

\begin{abstract}
Marshall and Newcombe (1973) described three forms of acquired dyslexia. Two of them (surface and deep dyslexia) have been the subject of much subsequent discussion, but the third (visual dyslexia) has largely been ignored. We report the case of patient $\mathrm{AB}$, who misread over $40 \%$ of words presented to her. The vast majority of her errors bore a close visually similarity to the target words. We present a detailed analysis of $\mathrm{AB}$ 's acquired dyslexia and consider whether it constitutes a distinct form of peripheral dyslexia or whether it can be accommodated within one of the recognised categories (e.g. neglect dyslexia).
\end{abstract}

\section{INTRODUCTION}

In their seminal paper on acquired dyslexia, Marshall and Newcombe (1973) described three forms of reading disorder. Two of them, "deep" and "surface" dyslexia, have been the object of intensive investigation ever since. In contrast, Marshall and Newcombe's third form of acquired dyslexia, "visual dyslexia", has received little attention or corroboration.

Marshall and Newcombe described two case of visual dyslexia. The reading errors of the first patient, JL, were described as "visual confusions" (e.g. DUG $\rightarrow$ "bug", BEG $\rightarrow$ "leg", WAS $\rightarrow$ "saw") together with occasional neologisms (e.g. MOW $\rightarrow$ "nume"). JL was reported to show a frequency effect in reading

Requests for reprints should be addressed to Dr M.A. Lambon Ralph, MRC Applied Psychology Unit, 15 Chaucer Road, Cambridge CB2 2EF, UK.

This study was conducted while the first author was in receipt of a studentship from the Engineering and Physical Sciences Research Council whilst at the University of York. We are grateful to Max Coltheart and two anonymous referees for hopeful comments on an earlier version of this paper. We would also like to thank Dr Linda Brown for her kind assistance, the staff at the day service that $\mathrm{AB}$ attended, and $\mathrm{AB}$ herself for her patience in participating in our study. 
accuracy, with common words being read more accurately than rarer words. Marshall and Newcombe's second patient, AT, showed a similar pattern of reading errors but did not show any overall effect of frequency on reading accuracy (see also Marshall \& Newcombe, 1977; Newcombe \& Marshall, 1975). Apart from this account, there have been few contemporary investigations of visual dyslexia although, as Marshall and Newcombe (1973) noted, other patients making predominantly visual errors had been reported in the past (e.g. Case \& Ettlinger, 1960; Simmel \& Goldschmidt, 1953; Thomsen \& Harmsen, 1968).

Cognitive neuropsychological account of acquired dyslexia recognize several qualitatively distinct forms of "peripheral dyslexia", that is, dyslexias that affect the initial recognition of letters and written word forms without necessarily affecting central semantic and phonological processes. The list of such dyslexias includes letter-by-letter reading (Howard, 1991; Patters on \& Kay, 1982), attentional dyslexia (Saffran \& Coslett, 1996; Shallice \& Warrington, 1977; Warrington, Cipolotti, \& McNeil, 1993), and neglect dyslexia (Ellis, Young, \& Flude, 1993; Warrington, 1991). The question then arises as to whether visual dyslexia should be regarded as a distinct form of acquired dyslexia or whether it can be subsumed under one of the more widely recognised categories.

Shallice (1988) argued that visual dyslexia may not, in fact, constitute a distinct form of acquired dyslexia. He noted (1988, p. 70, footnote 6) that Marshall and Newcombe's patient, AT, "appears to have bilateral lesions and potentially general visual problems", and observed that JL "had a right hemisphere lesion, and the errors he produced are typical of neglect dyslexia". The implication of his analysis is that visual dyslexia may not be a separate and distinct form of acquired dyslexia.

We present the case of patient $A B$, who made a very high proportion of visual errors in her reading. She was also impaired on a variety of tasks involving the recognition and matching of letters. We propose that $\mathrm{AB}$ 's visual errors can be accounted for in terms of impairment at the level of the visual analysis of letter forms, though we acknowledge that she also had other deficits, including a central semantic impairment. A range of tests are used to explore the similarities and differences between $\mathrm{AB}$ 's reading disorder and other, more widely recognised forms of acquired dyslexia.

\section{CASE HISTORY}

$\mathrm{AB}$, a right-handed woman aged 80 , was educated to the age of 14 years. She worked in her aunt's laundry until her marriage, after which she looked after her household and five children. She presented initially in February 1994 with poor long- and short-term memory, a slight dysphasia involving some wordfinding problems, and a degree of hearing loss. Her daughter reported that AB's 
memory had been declining over a period of some 10 years. Some form of dementia was suspected, perhaps multi-infarct in view of a history of vascular problems. AB had been a smoker with a history of angina (since 1984) and had suffered a myocardial infarction in December 1993.

The prominent present feature was a remarkably high number of visual errors when she tried to read single words aloud. Examples include RAKE $\rightarrow$ "rank", PARACHUTE $\rightarrow$ "parasol", SYRINGE $\rightarrow$ "spring", STIRRUP $\rightarrow$ "strip up" and CANOE $\rightarrow$ "can". These errors will be examined in detail later in the paper, but first we will discuss AB's processing of objects and spoken words. Testing was conducted from April to August 1995, after which time AB was unable to participate further for personal reasons.

\section{OBJECT RECOGNITION AND PROCESSING}

Patients who make visual errors in reading tasks may also make visual errors in recognising objects. We noted earlier Shallice's (1988) observation that Marshall and Newcombe's visual dyslexic, AT, appeared to have more general visual problems.

The minimal feature and foreshortened matching tests from the Birmingham Object Recognition Battery (Riddoch \& Humphreys, 1993) were given to AB. These tests require the subject to match a target view of an object to an alternative picture of the same item from a different view. According to Riddoch and Humphreys, good performance requires intact visual processing up to and including the formation of "object-centred" representations of the pictured items. $\mathrm{AB}$ scored $21 / 25$ on the minimal feature test (normal range 18-25) and 22/25 on the foreshortened matching test (normal range 16-25). Thus AB's visual analysis and comparison of objects was within normal limits.

$\mathrm{AB}$ was also given three tests of object naming. The first was the short picture naming test (no. 53) from the PALPA battery (Kay, Lesser, \& Coltheart, 1992). $\mathrm{AB}$ correctly named 35 of the 40 items, making three semantic errors, one circumlocution and one "no response" error. This is below normal limits (norms from PALPA mean $=39.8$, standard deviation $=0.35$ ). AB was also asked to name the target pictures from the PALPA word-to-picture matching test (no. 48). She scored 27/40, making 4 circumlocutions, 7 semantic, 1 phonological, and 1 visual error. Finally, AB was shown a separate selection of 100 line drawings, of which she named 65 correctly, making 17 semantic errors, 6 visual errors, 6 circumlocutions, 4 no responses, and 2 unclassified errors.

In sum, AB's object matching was largely preserved but she was impaired at object naming. She made seven purely visual errors in identifying a total of 180 pictures. Although normal subjects also make some visual errors, we note that this may be outside the normal range. It could also be argued that her 27 semantic errors could be partly visual in origin: semantically related objects 
tend also to be similar in appearance. We shall return to this point in the Discussion.

\section{SPEECH PROCESSING AND COMPREHENSION}

$\mathrm{AB}$ asked to repeat a mixed list of real words and nonwords (PALPA test 9). She correctly repeated 71/80 real words and 51/80 nonwords. Taking the limit of normal subjects as two standard deviations below the mean (figures from PALPA's young control subjects) suggests that $A B$ 's performance is just outside the normal range for words (lower limit 73/80) and clearly impaired for nonwords (lower limit 62/80). Nineteen of her 29 nonword repetition errors were lexicalisations, while the remainder were neologisms. AB also attempted to repeat a list used in the nonword reading task (PALPA test 36). She correctly repeated 17/24, with 6 lexicalisations and 1 neologism. AB's forward digit span was four.

Two tests of auditory comprehension were administered. The spoken wordto-picture matching test (PALPA no. 47) required her to point to one of five object pictures in response to a word spoken by the experimenter. The five pictures depict the target word (e.g. button), a close semantic distractor (zip), a more distant semantic distractor (bow), a visually similar object (a coin) and an unrelated object (a banknote). AB scored 29/40 (normal range 35-40) with 8 close semantic and 3 visual errors.

The auditory synonym judgement test (no. 49) involves the spoken presentation of pairs of words that the subject must classify as being similar or different in meaning. $\mathrm{AB}$ scored $15 / 30$ on the high imageability set and 8/15 on the low. Clearly, her performance on this test is at chance.

Thus, AB's perception and repetition of words and nonwords was impaired, though only mildly. In contrast, her comprehension of spoken words was severely impaired. AB's poor auditory comprehension suggests the presence of a central semantic deficit. We shall argue, however, that this semantic deficit was not responsible for the large number of visual errors $\mathrm{AB}$ made in reading.

\section{READING TASKS}

\section{Letter Processing}

A series of tests was administered that require the processing of single letters. These were taken from the PALPA battery (Kay et al., 1992). The first requires the subject to say whether letters are correctly oriented or mirror-reversed (test 18). AB scored 25/36, which is severely impaired and only just above chance (a score of 24/36 or over is significantly above chance).

Two further PALPA tests require the subject to match a letter to one of two alternatives presented in another case. Test 19 involves matching lower- to 
upper-case letters, while test 20 involves matching upper-case to lower-case letters. AB scored $17 / 26$ on test 19 and $11 / 26$ on test 20 . Neither of these scores is above that expected by chance. In PALPA test 22 the subject names all the letters of the alphabet in upper and lower case. AB named 10/26 lower-case letters and 18/26 upper-case letters correctly. On another occasion she named 16/26 upper-case letters correctly.

PALPA test 23 requires the subject to pick a letter from an array of four letters in response to a spoken letter name. $\mathrm{AB}$ did much better on this task, scored 23/26. When asked to copy upper-case letters, she scored 19/26. Her errors were all other, well-formed letters. When asked to write the letters of the alphabet to dictation, she managed 24/26.

In general, these tests show that $\mathrm{AB}$ had considerable problems in recognising individual letters. This suggests an impairment within the visual analysis system responsible for identifying letter forms. There is an interesting disparity between, on the one hand, her almost complete inability to distinguish correct from mirror-reversed letters or match upper- to lower-case letters and, on the other hand, her reasonable (though not normal) matching of spoken to written letters. We shall return to this contrast later.

\section{Reading Words Aloud}

Several test examined the effects of different word attributes on $\mathrm{AB}$ 's reading accuracy. In each test the words were presented in upper-cas e letters in the Arial font for $\mathrm{AB}$ to read aloud.

Distinctiveness and word frequency. The first test varied word frequency orthogonally with a measure of orthographic distinctiveness for a set of 90 3 -letter words. There were two levels of frequency (low = less than 15 occurrences per million words of English, high $=$ more than 30 per million: Kucera \& Francis, 1967). Distinctiveness was measured in terms of Coltheart's N count (the number of real words that can be created by changing single letters in a target word). There were three levels of $\mathrm{N}$ (less than 10 neighbours, between 12 and 19 neighbours, and more than 22 neighbours). Items were matched across the resulting 6 sets of 15 words. AB read 70/90 words correctly. Her accuracy did not vary significantly with either word frequency (low frequency 32/45, high frequency 38/45) or distinctiveness (low N23/30, medium N 22/30, high N 25/30). All her errors were real word paralexias (e.g. EWE $\rightarrow$ "few", $\mathrm{RIB} \rightarrow$ "ribbon", BOG $\rightarrow$ "dog", ERA $\rightarrow$ "egg”, DUE $\rightarrow$ "dunk", PIT $\rightarrow$ "pint").

Frequency, distinctiveness, and length. A second list of words varied frequency, distinctiveness, and letter length orthogonally. There were two 
levels of frequency (low = less than 12; high = greater than 15$)$ and two levels of distinctiveness (low $\mathrm{N}=1-10$ orthographic neighbours, high $\mathrm{N}=11-19$ neighbours). Frequency and $\mathrm{N}$ were matched pairwise for words of two letter lengths ( 3 or 5 letters). AB read 41/96 words correctly. She again showed no significant effect of frequency (low 20/48; high 21/48) or distinctiveness (low $\mathrm{N} 20 / 48$; high $\mathrm{N}=21 / 48$ ), and the trend towards better reading of 5- than 3 -letter words was not significant (3-letter 17/48, 5-letter 24/48). AB made 53 real word paralexias (e.g. ORB $\rightarrow$ "order", OVA $\rightarrow$ "oven", HEY $\rightarrow$ "hen", $\mathrm{JOB} \rightarrow$ "hob") and 2 "no response" errors.

Frequency, imageability, and length. Frequency and length were again investigated in a third list of 192 words that also varied imageability (ratings on a 7-point scale from Quinlan, 1992). There were two levels of frequency (low = less than 19; high $=$ more than 20), three levels of lengths $(4,6$, and 8 letters), and two levels of imageability (low = less than 4.85 [mean 3.9]; high $=$ greater than 5 [mean 5.7]). Items were matched pairwise across all three factors, with frequency being matched for logarithmic as well as absolute values. AB read 94/192 words correctly. On this occasion she showed significant effects of both frequency (low 38/96; high 57/96; $\chi^{2}=11.9, P<.01$ ) and imageability (low 32/96; high 63/06; $\chi^{2}=18.8, P<.01$ ) but no significant effect of word length (4-letter 28/64; 6-letter 36/64; 8-letter 31/46). Again the vast majority of her errors $(N=87)$ were real word paralexias (e.g. IMMUNITY $\rightarrow$ "immediately", OPTIMISM $\rightarrow$ "optimistic", BOUNDARY $\rightarrow$ "embroidery", SOCK $\rightarrow$ "shock"), her other errors being either no responses $(N=6)$ or nonword paralexias $(N=4)$.

Regularity, frequency, and imageability. Two lists from Strain, Patters on, and Seidenberg (1995) were used to assess the effects of regularity, frequency, and imageability on AB's reading accuracy. The first list manipulated all three variables orthogonally. $\mathrm{AB}$ read 53/96 words from this list correctly. She showed a significant effect of frequency (high $35 / 48$; low $18 / 48 ; \chi^{2}=10.8, P$ $<.01$ ) and a trend towards better reading of concrete than abstract words that was not, however, significant (high imageability 32/48; low 21/48). There was no effect of regularity (regular 28/48; exceptional 25/48). Thirty-four of her 43 errors were real word paralexias (e.g. TRUCE $\rightarrow$ "trust", SCORN $\rightarrow$ "corn", GUISE $\rightarrow$ "guest", SUAVE $\rightarrow$ "slave") and 9 were nonword paralexias.

The second list varied regularity and imageability for low-frequency words only. AB read 22/64 words correctly. This time the effect of imageability was significant (high $16 / 32$; low $6 / 32: \chi^{2}=5.6, P<.01$ ). There was no effect of regularity (regular 12/32, exceptional 10/32). Thirty-nine of her 42 errors were real word paralexias (e.g. WRATH $\rightarrow$ "weather", MERCY $\rightarrow$ "merry", BROADER $\rightarrow$ "bother"): the remaining 3 errors were nonword paralexias. 
Imageability and age of acquisition. $\mathrm{AB}$ showed a significant effect of imageability in two of the previous three tests and a nonsignificant trend in the other. Those lists did not, however, control for age of acquisition. Imageability correlates highly with age of acquisition because abstract words tend to be learned later in life than concrete words, and age of acquisition is a powerful determinant of the speed and accuracy of normal word recognition (see Morrison \& Ellis, 1995).

The final reading test varied age of acquisition and imageability orthogonally (values from Quinlan, 1992) while controlling letter length and frequency (absolute and $\log$ values). There were two levels of age of acquisition (early = $1.8-4.0$ on a 7-point scale; late $=4.0-5.25$ ) and two levels of imageability (low $=3.5-5.5$; mean $=5.0$; high $=5.5-6.25 ;$ mean $=5.9)$. Note that the natural correlation between these variables is such that it is impossible to achieve a strong manipulation of imageability while controlling age of acquisition (and frequency). $\mathrm{AB}$ read 62/96 words correctly, showing no effect of imageability once age of acquisition was controlled (low 30/48; high 32/48) but a significant effect of age of acquisition with imageability controlled (early 39/48; late 23/48: $\left.\chi^{2}=10.2, P<.01\right)$. Of her 34 errors, 23 were real word paralexias (e.g. CONCERT $\rightarrow$ "consent", TAPE $\rightarrow$ "tab", PLANET $\rightarrow$ "plant", GRAVY $\rightarrow$ "grave"), 9 were nonword paralexias, and 2 were no responses.

Summary and regression analysis. Overall, there was no indication that $\mathrm{AB}^{\prime} \mathrm{s}$ reading accuracy was affected by distinctiveness, regularity, or the number of letters in a word. Imageability exerted a significant influence in two reading tests, and a nonsignificant trend in a third, but when imageability and age of acquisition were unconfounded, only an effect of age of acquisition was observed (though we have noted that it was not possible to achieve a strong manipulation of imageability on this occasion). A significant advantage for high- over low-frequency words was observed in two of the four tests in which frequency was manipulated.

In an attempt to resolve the ambiguities surrounding the effects of different variables on $A B$ 's reading, her performance on all the various word lists (474 words in total) was used as the dependent measure in a logistic regression analysis that had age of acquisition, imageability, log word frequency, letter length, and distinctiveness as the predictor variables. AB read a total of 269 (57\%) of the words correctly. Her reading accuracy showed significant raw correlations with age of acquisition $(r=-.37, P<.001)$, imageability $(r=+$ $.34, P<.001),(\log )$ frequency $(r=+.20, P<.001)$, and number of neighbours $(r=+.17, P<.001)$, but not letter length $(r=-.08, P=.09)$. Raw correlations must, however, be viewed with caution when the predictor variables are themselves significantly correlated.

Like other regression analyses, logistic regression produces a regression equation from the linear combination of the predictor variables, which then 
predicts the patient's accuracy for each word. Taken together, the variables showed a significant capacity to predict which words $\mathrm{AB}$ read correctly and which incorrectly (model $\chi^{2}=87.1, P<.001$ ). The significance of the independent contributions of the predictor variables is assessed using the Wald statistic. There were significant independent effects of age of acquisition (Wald $=13.5, P=.0002)$, imageability $(\mathrm{Wald}=6.2, P=.01)$ and $(\log )$ frequency (Wald $=12.4, \mathrm{P}=.0004)$. When these three other lexical variables were taken into account, distinctiveness and letter length did not make significant contributions. Although we have expressed some reservations elsewhere about the use of regression analyses with single case data (Ellis, Lum, \& Lambon Ralph, 1996), our tentative conclusion is that AB's reading accuracy was affected by age of acquisition, imageability, and frequency, but not by distinctiveness, regularity, or letter length.

\section{Letter Length and Reading Speed}

Letter-by-letter readers show a marked effect of letter length on the speed with which words can be identified (Howard, 1991). AB was asked to read lists of six 3- to 6-letter words (PALPA test 29) and her reading speed for each list was timed with a stopwatch. She read the words fairly rapidly and accurately, making just one visual paralexia (PRIEST $\rightarrow$ "press") $)^{1}$, but she showed no trace of an effect of letter length on reading speed (total time for six 3-letter words $=7 \mathrm{sec} ;$ 4-letter words $=7 \mathrm{sec} ; 5$-letter words $=5 \mathrm{sec} ; 6$-letter words $=6 \mathrm{sec}$ ).

\section{Reading Flanked Letters and Grouped Words}

Patients with "attentional dyslexia" have difficulty identifying letters that are flanked by other letters, and letters may "migrate" from one position to another when the patients are reading groups of words (Saffran \& Coslett, 1996; Shallice \& Warrington, 1977; Warrington et al., 1993). The possibility that AB was an attentional dyslexic was examined using two tests. The first compared the naming of individually presented letters with her naming of letters flanked by four other letters (two to the left and two to the right of the letter that $\mathrm{AB}$ was asked to name). The second test compared AB's reading of words presented individually on one occasion and in groups of four (arranged two above and two below) on another occasion.

In the first task $\mathrm{AB}$ showed no difference between naming individual letters $(17 / 26)$ or flanked letters $(20 / 26)$. None of her errors involved the migration of letters from one position to another. In the second task, she was unaffected by

${ }^{1}$ It is interesting that $\mathrm{AB}$ achieved such a high level of accuracy on the one occasion that she was asked to read words aloud as rapidly as possible. With hindsight it is unfortunate that we did not follow this up. 
manner of presentation, reading 9/20 words presented on their own and 11/20 words presented in groups.

\section{Reading Nonwords}

If $\mathrm{AB}$ has an impairment affecting the visual analysis system, she should show poor reading of nonwords as well as of real words. One might indeed predict that nonword reading would be especially sensitive to impaired letter recognition, because real words have a much better chance of being guessed correctly from degraded input than nonwords. $\mathrm{AB}$ was asked to read a list of 24 nonwords that vary in length from 3 to 6 letters (PALPA test 36) but was unable to read any of them correctly. Nineteen of her errors were lexicalisation (e.g. BEM $\rightarrow$ "Ben", DOOP $\rightarrow$ "dump", SMODE $\rightarrow$ "smoking", CHURSE $\rightarrow$ "church"), three were "no responses", and two were alternative but incorrect nonwords. We note that she repeated 17 of these 24 nonwords correctly when they were presented in spoken form (see earlier), so problems of a phonological nature cannot explain her complete inability to read any of the nonwords correctly.

\section{Comprehension of Written Words}

$A B$ 's comprehension of written words was tested using the written version of the word-to-picture matching test (PALPA test 48). AB was asked to read aloud the object name printed in the centre of each page and then to select the target picture from the set of five that surround the word. $A B$ read 28 of the 40 words correctly. On 20/28 trials when the word was read correctly she went on to choose the correct picture, but she incorrectly selected a close semantic distractor on 6 trials and a distant semantic distractor on 2 trials. On 6 of the 12 trials where $\mathrm{AB}$ misread the object name she nevertheless chose the correct picture. On the remaining six trials she selected two close semantic distractors, three distant semantic distractors and one visual distractor. Thus, AB made 26 correct picture selections overall. This score is above chance, and similar to the score she obtained in the spoken word-to-picture matching version of the same test (29/40), but is again well below the normal range (35-40).

On eight of the trials where $\mathrm{AB}$ read the central word correctly she went on to select a semantically related distractor picture, avoiding the visual and unrelated distractors. This might be taken as further evidence for a central semantic impairment. Of interest is the fact that the 12 trials where she misread the target word were accompanied by 6 correct picture selections and 5 selections of semantically related items. This could be construed as indicating that when $\mathrm{AB}$ made a reading error, there was nevertheless some activation of the meaning of the target word. There are, however, alternative explanations. When $\mathrm{AB}$ had attempted to read the word and then moved to looking at the pictures she did not necessarily ignore the word. If she could not find a picture corresponding to the meaning of her reading error she may have re-fixated the 
word and made another attempt to read it (to herself ). This second attempt may have been facilitated by the pictures. One observation illustrates the iterative process we think may explain the selection of pictures matching or related to words that were initially misread. One target item is the word HAMMOCK. $\mathrm{AB}$ 's initial reaction was "I can't get that", but having looked at the pictures she said "oh, hammock ... that one". Seeing the picture of the hammock seemed to have primed identification of the word. ${ }^{2}$

\section{TOP-DOWN INFLUENCES ON AB'S READING ACCURACY}

The fact that $\mathrm{AB}$ had great difficulty with some of the letter recognition tasks might be taken to indicate that the early stage of featural analysis of letters was impaired. If $\mathrm{AB}$ was operating with degraded visual input, then it was thought possible that she would show similar effects to those that have been reported in normal subjects when words are presented very briefly or in some other degraded format. The two effects that were investigated in $\mathrm{AB}$ were the "word superiority effect" in letter recognition and semantic priming in reading single words aloud.

\section{Word Superiority Effect}

If a string of letters is presented for a brief period, followed by a visual "mask" of letter fragments, normal subjects are better able to identify specific letters when the string is a real word or a word-like pseudoword (e.g. SPCT) than when it is an orthographically illegal strong of letters that bears little resemblance to any real word (e.g. QPJX). This is the word superiority effect (McClelland \& Rumelhart, 1981; Reicher, 1969).

Rumelhart and McClelland (1982) proposed that the word superiority effect arises because pseudowords share a greater orthographic similarity to real words than illegal nonwords do. Within their computational model, pseudowords benefit from the fact that they cause considerable activation of word-level units for visually similar words. Feedback from the word unit to letter units contributes top-down activation to those units, meaning that less bottom-up activation from the feature level is required for a letter to be identified. Thus, the pseudow ord SPCT differs by a single letter from the words SPAT, SPOT, and SPIT, and by two letters from words such as SPIN, SPUN, and SPAM. The word units for all of those words will be activated to some degree by SPCT and contribute activation to the component letter units. In

${ }^{2}$ The way to test this would be to remove the written word before asking the patient to select the matching picture. Unfortunately $\mathrm{AB}$ is no longer available, so we are unable to do this. 
contrast, the illegal nonword QPJX has many fewer orthographic neighbours and so its letter units will benefit much less from top-dow $n$ activation. The result is that if the task is to identify the second letter of SPCT or QPJX from a brief, masked presentation, the letter unit for $\mathrm{P}$ will have gained more top-down activation from the many neighbours of SPCT than from the few, distant neighbours of QPJX.

Other researchers have tried to show the word superiority effect in patients with acquired dyslexia, notably letter-by-letter readers. Early studies produced rather negative results (Levine \& Calvanio, 1978; Warrington \& Shallice, 1980), but later studies, which used limited exposure durations and pattern masks, obtained more positive results (e.g. Bowers, Bub \& Arguin, 1996; Reuter-Lorenz \& Brunn, 1990). Bowers et al. (1996) have also reported a word superiority effect in a patient who combined letter-by-letter reading with surface dyslexia.

We tested $\mathrm{AB}$ for a word superiority effect using a simple paper-based test. Four kinds of letter strong were employed: high-frequency words, low-frequency words, word-like pseudowords created by changing single letters of real words (e.g. FUGHT), and orthographically illegal nonwords (e.g. OTMYT). The two word list were matched as closely as possible for letter length, Coltheart's N, and imageability. Twenty-two letters were tested at first and third positions, excluding Z, X, J, and Q. The task was simply to look at each fouror five-letter string and report whichever letter was underlined (either the first or the third). If the string was a real word, $A B$ was asked to read it aloud after identifying the underlined letter. Exposure duration was not limited, and no masking was used in the procedure.

$\mathrm{AB}^{\prime} \mathrm{s}$ accuracy of reporting the letters was not affected by letter position across the different string types (first position $88 \%$; third position $89 \%$ ), but her accuracy varied with string type (pseudowords 40/44; illegal nonwords $31 / 44$ ). $A B^{\prime} s$ identification of letters in real words (high frequency $=42 / 44$; low frequency $=43 / 44)$ and pseudowords $(40 / 44)$ were all significantly better than her identification of letters in illegal nonwords $(31 / 44$ binomial, $P<.01$ for each comparison). Taking $\mathrm{AB}$ 's average single letter naming at $62 \%$ (measured across five separate lists), there was no significant difference between single letter identification and identification of letters in illegal nonwords $(P=.15)$, but there was a significant difference in accuracy compared with real words $(P<.001)$ and pseudowords $(P<.001)$.

$\mathrm{AB}^{\prime} \mathrm{s}$ letter identification was significantly better for letters presented in real words or pseudowords than in illegal nonwords or in isolation. This effect was found despite the fact that on other occasions $A B$ was unable to read any pseudowords correctly. Her performance was no worse when the letters were presented in nonword strings than when they were presented in isolation, replicating the previous finding that she read flanked letters with equal accuracy to individual letters. Although her letter reading in low- and high-frequency 
words was identical, her reading of the words was on this occasion more accurate for high-frequency words (38/44) than low-frequency words $(13 / 44$; $\left.\chi^{2}=26.9, P=<.01\right)$, though we note that these word sets were not matched on age of acquisition. Thus, the word superiority effect found in $A B$ was independent of her ability to read the strings aloud correctly.

\section{Semantic Priming}

A context effect seemed to be present when $\mathrm{AB}$ was given the word-to-picture matching task. Thus, on some occasions she seemed to be helped by the presence of a picture of the word, as when her reading of the word HAMMOCK was facilitated by seeing a picture of it. The possibility of semantic priming was tested more formally by asking $\mathrm{AB}$ to read the words from the PALPA word-to-picture matching test on two separate occasions, once with no cue and once with a semantic cue spoken by the experimenter. Each cue gave a degree of semantic information (e.g. superordinate category) that might help her reading but was insufficient for the word to be guessed from the cue itself. For example, for the word "carrot" she was told that it was a vegetable; for "hat", she was told that it was something to wear. When reading the words without priming she managed $28 / 40$, but with the semantic cue she was able to read $36 / 40$ correctly. This difference is significant (binomial, $P=.004$ ). As predicted, AB's word reading was helped by semantic priming.

\section{ERROR ANALYSIS}

Shallice (1988) likened the reading errors of Marshall and Newcombe's (1973) patient JL to those of patients with neglect dyslexia. The diagnosis of neglect dyslexia is based primarily upon an analysis of reading errors. AB's real word errors to word targets were combined across various word lists to form a corpus of 208 errors on which further analysis could be carried out. The corpus is provided in the Appendix.

Most of $A B$ 's errors bore a clear visual similarity to the target word. In order to measure this formally we adopted the criterion that at least half the letters in the error must be present in the target word for it to be counted as a visual error. On this criterion 194/208 (93\%) of AB's errors were visual errors. All of the remaining lexical responses shared some letters with their targets, but not enough to be classified as visual under the $50 \%$ criterion (e.g. DUD $\rightarrow$ "doll", INFINITY $\rightarrow$ "interview"). A few of her errors could be classed as morphological (e.g. WEALTH $\rightarrow$ "wealthy", STANZA $\rightarrow$ "stanzas"), but too few in our opinion to support any strong claim that morphological errors should be recognised as a distinct category of error for AB (cf. Funnell, 1987). Only two of AB's 208 real-word errors could conceivably be regarded as semantic in nature (MOTOR $\rightarrow$ "trolley" and CELLAR $\rightarrow$ "ceiling"). In both of these 
cases the semantic connection is a tenuous one, and almost certainly a matter of chance (cf. Ellis \& Marshall, 1978).

Patients with neglect dyslexia make visual errors that affect one end of a word more than the other (Ellis et al., 1993). Most commonly the neglect is of the left side, so that the target and error words share the same end letters but differ at the beginning. For example, patient VB of Ellis, Flude, and Young (1987) misread LOG as "dog" and YELLOW as "pillow". But some patients have been reported whose errors tend to diverge from the targets at the end rather than the beginning (e.g. Warrington, 1991). Inspection of the target and error words listed in the Appendix shows that $85 \%$ of $\mathrm{AB}^{\prime} \mathrm{s}$ errors shared the same initial letter as the target word while $42 \%$ shared the same final letter. Thus, AB's errors were more similar to the target words at the beginning than at the end. This means that if $\mathrm{AB}$ is to be considered as a possible case of neglect dyslexia, then the comparison must be with patients whose errors are concentrated at the ends of words. One such is Warrington's (1991) patient RYT, whose errors typically shared the same initial letters but diverged towards the ends (e.g. BLOW $\rightarrow$ "blue", SQUARE $\rightarrow$ "squash"). Warrington showed that the probability of a letter in a target word being incorporated in RYT's error declined steeply from close to $100 \%$ for initial letters to less than $20 \%$ for final letters. This was true for words varying in length from 3 to 7 letters.

In order to compare $\mathrm{AB}$ directly with RYT, an analysis was carried out to determine the probability that letters from different positions of target words will appear in the errors made to those words. A letter in a given position in a target word was deemed to have appeared in the error if the letter occurred anywhere in the error, irrespective of position. For RYT, this analysis was done separately for target words of three to seven letters (taken from Appendix A, Corpus 2 of Warrington, 1991). For AB, the same analysis was done on all the errors of three to six letters in lengths, plus eight-letter words (listed in the Appendix to this paper). ${ }^{3}$ The results are shown in Fig. 1. RYT's errors show the strong effect of serial position reported by Warrington, with initial letters being more likely to be preserved in the error than final letters at all letter lengths. $\mathrm{AB}$ also shows a trend across serial positions, but it is much less pronounced than RYT's, with 55-78\% of word-final letters from words shown to $\mathrm{AB}$ being reproduced in her errors, compared with $18-31 \%$ for RYT.

Ellis et al. (1987) proposed a strict criterion for identifying clear neglect errors, namely that the target and error words should be identical to one side of a pair of imaginary "neglect points" in the two words and should share no letters

${ }^{3} \mathrm{AB}$ made only eight errors to seven-letter targets, while seven-letter words were the longest shown to RYT. Hence in order to compare performance at the longest word length for which reasonable numbers of errors are available for the two patients we have compared RYT's errors to seven-letter words with $\mathrm{AB}$ 's errors to eight-letter words. 
(A)

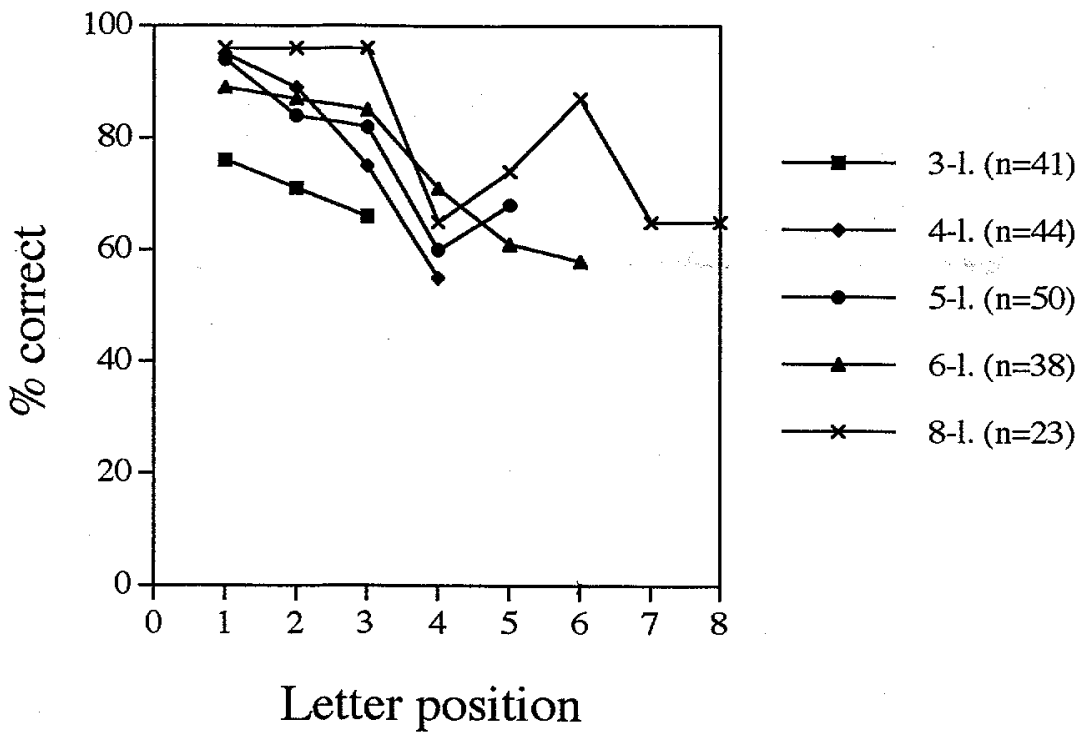

(B)

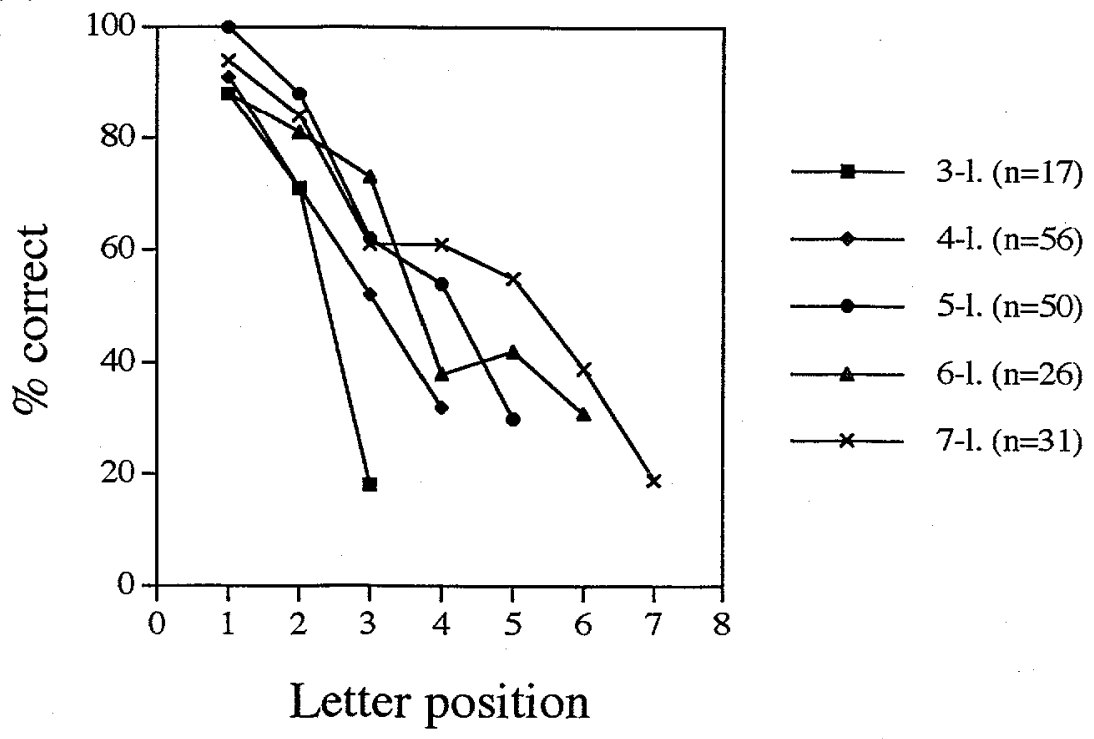

FIG. 1. The effect of serial position on the probability that a letter in the target word will appear in the error made to that word. Fig. 1A shows the results for patient AB; Fig. 1B the results for patient RYT (Warrington, 1991). 
in common to the other side. For example, in the neglect dyslexic error YELLOW $\rightarrow$ "pillow", the two words are identical to the right of neglect points placed between the E and L in YELLOW and between the I and L in PILLOW but share no letters in common to the left of those two neglect points. Corpus 2 of the Appendix to Warrington (1991) lists 181 substantive errors from RYT (excluding omissions). Ninety-seven of these errors (54\%) satisfy the strict criterion for being classed as neglect errors. Of them, 96 are right neglect errors, which are identical to the left of two neglect points and share no letters to the right (e.g. ARM $\rightarrow$ "arch", FINALLY $\rightarrow$ "finance"); there is just a single error that satisfies the criterion for classification as a left neglect error (SIDE $\rightarrow$ "guide"). In comparison, the Appendix to the present paper lists 208 substantive errors from $\mathrm{AB}$, of which $86(41 \%)$ can be classed as neglect errors using the strict criterion. Of these, 71 are right neglect errors (e.g. BURN $\rightarrow$ "bury", SWORD $\rightarrow$ "swan") while 15 are left neglect errors (e.g. JOB $\rightarrow$ "hob", PAT $\rightarrow$ "bat"). Thus, while the ratio of right to left neglect errors is 96:1 for RYT, for $\mathrm{AB}$ it is just 4.7:1.

\section{DISCUSSION}

$\mathrm{AB}$ misread over $40 \%$ of single words presented to her. Over $90 \%$ of her reading errors could be classified as visual errors on the basis that they shared at least half the letters of the target word. The remainder of her errors also shared some letters in common with their targets, and an inspection of $\mathrm{AB}$ 's errors suggests that there is no need to recognise any other category of errors (such as morphological, regularisation, or semantic error).

$\mathrm{AB}^{\prime}$ s problems were not purely visual or orthographic, however. Her impaired repetition of words and (particularly) nonwords points to a phonological impairment, while her poor auditory synonym judgements and word-picture matching (where her errors mostly involved the selection of close semantic distractors) suggest a central semantic deficit. $\mathrm{AB}$ adds to the list of different patterns of reading that have been observed to co-occur with semantic impairment, including deep dyslexia (Plaut \& Shallice, 1993), phonological dyslexia (Funnell, 1983), surface dyslexia (Patterson \& Hodges, 1992), and intact reading aloud (e.g. Cipolotti \& Warrington, 1995; Lambon Ralph, Ellis, \& Franklin, 1995; Raymer \& Berndt, 1996). Such a variety of reading patterns co-existing with semantic impairment must make it increasingly difficult to sustain the argument that a semantic deficit along predisposes a patient towards any particular form of acquired dyslexia.

$\mathrm{AB}^{\prime} \mathrm{s}$ semantic impairment is likely to have played a part in causing her to make semantic errors in object picture naming. We noted earlier, however, that $\mathrm{AB}$ also made some purely visual naming errors. Semantically related objects tend to be similar in appearance, making it difficult in practice to force a clear distinction between visual and semantic naming errors, and difficult to deter- 
mine which errors have a visual origin and which a semantic origin. $\mathrm{AB}$ is not a strong case with whom to dispute Shallice' s (1988) point that visual paralexias may have their origins in more general visual problems, and not a strong case with whom to address the question of which, if any, of the processes involved in reading are specific to visual word recognition (for discussion see Farah, Stowe, \& Levinson, 1996; Farah \& Wallace, 1991).

As well as making abundant visual errors in reading, $A B$ was severely impaired at naming individual letters, matching upper- to lower-case letters, and at judging whether letters were normal or mirror reversed. It is clear that her visual or orthographic impairment affected the early stage of identifying letters from their component features. One might expect that impaired visual analysis could be overcome to some extent by "top-down" influences. We have demonstrated that $\mathrm{AB}$ showed the classic top-down effect on letter recognition-the word superiority effect: she was considerably better at identifying letters presented in words or pseudowords than letter presented singly or as part of illegal nonwords. We noted earlier that $\mathrm{AB}$ was better at selecting letters in response to spoken names than at naming or matching them. This may also represent a top-down effect: when the target letter was spoken, that may have activated its mental representation sufficiently to distinguish it from other letters in the array.

In addition, $\mathrm{AB}$ showed semantic priming of word recognition, which we would attribute to a top-down influence at the word level. She read words more accurately when given a very general semantic cue than when reading them in isolation. She also seemed to use semantic priming on occasions to overcome her visual analysis problems; for example scanning the pictures of a wordpicture matching test to help her identify the written word in the centre of the pictures.

The analysis of which factors did or did not affect AB's reading accuracy seemed to reveal effects of age of acquisition, frequency, and imageability but not distinctiveness, regularity, or letter length. We are inclined to attribute the effect of imageability to an involvement of the semantic system in AB's reading (cf. Plaut \& Shallice, 1993). She was very poor indeed at reading nonwords, implying that her word reading relied almost exclusively on lexical processes. Given her additional semantic impairment, any involvement of semantic representations in reading aloud is likely to have favoured concrete over abstract words.

Theoretical accounts of age of acquisition in normal subjects have tended to suggest that it exerts its effect at the level of the retrieval of phonological word-forms (Brown \& Watson, 1987; Morrison \& Ellis, 1995). Frequency may also influence that stage of processing (Barry, Morrison, \& Ellis, 1997). One possible explanation of how those variables could come to influence AB's reading is that a combination of reduced or noisy input from the visual analysis system and a diminished contribution from semantics culminated in reduced 
activation of phonological representations for output. When a phonological word-form could not be activated because it was of low frequency or late age of acquisition, spreading activation within the visual input lexicon may have activated other lexical entries, causing a visual error. This is reminiscent of the explanation of visual errors in deep dyslexia offered by Morton and Patterson (1980).

An alternative, or additional, explanation of the frequency and age of acquisition effects in $A B$ 's reading would place their locus at the level of the visual input lexicon. Yamazaki, Ellis, Morrison, and Lambon Ralph (1997) have argued that although the age at which a word is learned in speech affects the subsequent ease of activating its phonological representation, the age at which a child learns to read that word may affect the subsequent ease of activating its orthographic representation. On this account, $A B$ 's age of acquisition and frequency effects would reflect the ease with which degraded inputs could access the representations of the target words in her orthographic (visual input) lexicon.

$\mathrm{AB}$ showed no effect of word length on her reading speed or accuracy, so cannot be regarded as a letter-by-letter reader. There was no effect of flanking on her ability to recognise letters, and no movement of letters between words in groups, so attentional dyslexia can be excluded. The question of whether she should be regarded as a case of neglect dyslexia is more difficult to answer. We have devoted a considerable amount of time to a comparison between AB's reading errors and those of the neglect dyslexic patient who might be considered to be more similar to AB, namely Warrington's (1991) case RYT.

The errors of both patients tended to affect the ends of words more than their beginnings, but this was considerably more pronounced for RYT than for AB. Between 88 and $100 \%$ of RYT's errors to words contained the initial letter of the target word, compared with 76 to $100 \%$ for $\mathrm{AB}$. But AB also reproduced between 55 and $78 \%$ of final letters correctly whereas RYT could manage only 18-31\% (see Fig. 1). The left-right gradient that lead RYT to be classed as a case of right-side neglect dyslexia was therefore considerably less marked in $\mathrm{AB}$. This was reflected in the numbers of errors that could be classified as left or right neglect errors using Ellis et al.'s (1987) strict criterion. The ratio of right to left neglect errors was 96:1 for RYT, compared with just 4.7:1 for AB.

One might argue that RYT was just a more severe case of right neglect dyslexia than $\mathrm{AB}$, and therefore showed a more pronounced left-right gradient and a higher proportion of right neglect errors. We note, however, that $\mathrm{AB}$ and RYT had very similar levels of overall reading accuracy: RYT correctly read $52 \%$ of single words shown to her while AB managed $57 \%$. Thus RYT's much

${ }^{4}$ Note that neither AB not RYT showed signs of neglect on other, non-reading tasks. 
more obvious right neglect dyslexia was associated with a level of reading accuracy that was only slightly worse than $A B$ 's.

If $\mathrm{AB}$ and $\mathrm{RYT}$ are to be placed in the same category of "right neglect dyslexia" then it would be necessary to show how two such different left-right gradients could co-exist with such similar levels of reading accuracy. One way forward would be to explore the effects on accuracy of different gradients of left-right activation within a computational model such as that of Mozer and Behrmann (1990; Behrmann, Moscovitch, \& Mozer, 1991). If the gradient can be varied independently of the overall accuracy level, then perhaps visual dyslexia could be seen as occupying a point on a continuum between left neglect dyslexia and right neglect dyslexia, being characterised by the same fundamental deficit but with less of a spatial gradient.

We hope that this report will encourage others to investigate patients who make a high proportion of visual errors in reading without being letter-by-letter readers or attentional dyslexics. The categories of deep and surface dyslexia that Marshall and Newcombe (1973) introduced into the literature are now secure and widely recognised. It is still unclear what fate awaits the Cinderella of the trio, visual dyslexia.

Manuscript first received 6 February 1996

Revised manuscript received date 25 June 1997

Revised manuscript accepted 21 August 1997

\section{REFERENCES}

Barry, C., Morrison, C.M., \& Ellis, A.W. (1997). Naming the Snodgrass and Vanderwart pictures: Effects of age of acquisition, frequency and name agreement. Quarterly Journal of Experimental Psychology, 50A, 560-585.

Behrmann, M., Moscovitch, M., \& Mozer, M.C. (1991). Directing attention to words and nonwords in normal subjects and in a computational model. Cognitive Neuropsychology, 7 , 213-248.

Bowers, J.S., Bub, D.N., \& Arguin, M. (1996). A characterisation of the word superiority effect in a case of letter surface alexia. Cognitive Neuropsychology, 13, 415-441.

Brown, G.D.A., \& Watson, F.L. (1987). First in, first out: Word learning age and spoken word frequency as predictors of word familiarity and word naming latency. Memory and Cognition, $15,208-216$.

Casey, T., \& Ettlinger, G. (1960). The occasional "independence" of dyslexia and dysgraphia from dysphasia. Journal of Neurology, Neurosurgery and Psychiatry, 23, 228-236.

Cipolotti, L., \& Warrington, E.K. (1995). Semantic memory and reading abilities: A case report. Journal of the International Neuropsychological Society, 1, 104-110.

Ellis, A.W., Flude, B.M., \& Young, A.W. (1987). "Neglect dyslexia" and the early visual processing of letters in words and nonwords. Cognitive Neuropsychology, 4, 439-464.

Ellis, A.W., Lum, C., \& Lambon Ralph, M.A. (1996). On the use of regression techniques for the analysis of single case aphasic data. Journal of Neurolinguistics, 9, 165-174.

Ellis, A.W., \& Marshall, J.C. (1978). Semantic errors or statistical flukes? A note on Allport's "On knowing the meaning of words we are unable to report". Quarterly Journal of Experimental Psychology, 30, 569-575. 
Ellis, A.W., Young, A.W., \& Flude, B.M. (1993). Neglect and visual language. In I.H. Robertson \& J.C. Marshall (Eds.), Unilateral neglect: Clinical and experimental studies. Hove, UK: Lawrence Erlbaum Associates Ltd.

Farah, M.J., Stowe, R.M., \& Levinson, K.L. (1996). Phonological dyslexia: Loss of a readingspecific component of the cognitive architecture? Cognitive Neuropsychology, 13, 849-868.

Farah, M.J., \& Wallace, M.A. (1991). Pure alexia as a visual impairment: A reconsideration. Cognitive Neuropsychology, 8, 313-334.

Funnell, E. (1983). Phonological processes in reading: New evidence from acquired dyslexia. British Journal of Psychology, 74, 159-180.

Funnell, E. (1987). Morphological errors in acquired dyslexia: A case of mistaken identity. Quarterly Journal of Experimental Psychology, 39A, 497-538.

Howard, D. (1991). Letter-by-letter readers: Evidence for parallel processing. In D. Besner \& G.W. Humphreys (Eds.), Basic processes in reading: Visual word recognition. Hillsdale, NJ: Lawrence Erlbaum Associates Inc.

Kay, J., Lesser, R., \& Coltheart, M. (1992). PALPA: Psycholinguistic Assessments of Language Processing in Aphasia. Hove, UK: Lawrence Erlbaum Associates Ltd.

Kucera, H., \& Francis, W. (1967). Computational analysis of present-day American English. Providence, RI: Brown University Press.

Lambon Ralph, M.A., Ellis, A.W., \& Franklin, S. (1995). Semantic loss without surface dyslexia. Neurocase, 1, 363-369.

Levine, D.N., \& Calvanio, R. (1978). A study of the visual defect in verbal alexia-simultanagnosia. Brain, 101, 65-81.

Marshall, J.C., \& Newcombe, F. (1973). Patterns of paralexia: A psycholinguistic approach. Journal of Psycholinguistic Research, 2, 175-199.

Marshall, J.C., \& Newcombe, F. (1977). Variability and constraint in acquired dyslexia. In H. Whitaker \& H.A. Whitaker (Eds.), Studies in neurolinguistics, Vol. 3. New York: Academic Press.

McClelland, J.L., \& Rumelhart, D.E. (1981). An interactive activation model of context effects in letter perception: Part 1. An account of basic findings. Psychological Review, 88, 375-407.

Morrison, C.M., \& Ellis, A.W. (1995). The roles of word frequency and age of acquisition in word naming and lexical decision. Journal of Experimental Psychology: Learning, Memory and Cognition, 21, 116-133.

Morton, J., \& Patterson, K.E. (1980). A new attempt at an interpretation, or, an attempt at a new interpretation. In M. Coltheart, K.E. Patterson, \& J.C. Marshall (Eds.), Deep dyslexia. London: Routledge \& Kegan Paul.

Mozer, M.C., \& Behrmann, M. (1990). On the interaction of selective attention and lexical knowledge: A connectionist account of neglect dyslexia. Journal of Cognitive Neuroscience, 2, 96-123.

Newcombe, F., \& Marshall, J.C. (1975). Traumatic dyslexia: Localization and linguistics. In K.J. Zülch, O. Creutzfeldt, \& G.C. Galbraith (Eds), Cerebral localisation. Berlin: Springer-Verlag.

Patterson, K., \& Hodges, J.R. (1992). Deterioration of word meaning: Implications for reading. Neuropsychologia, 30, 1025-1040.

Patterson, K.E., \& Kay, J. (1982). Letter-by-letter reading: Psychological descriptions of a neurological syndrome. Quarterly Journal of Experimental Psychology, 34A, 411-441.

Plaut, D.C., \& Shallice, T. (1993). Deep dyslexia: A case study of connectionist neuropsychology. Cognitive Neuropsychology, 10, 377-500.

Quinlan, P.T. (1992). The MRC psycholinguistic database. London: Oxford University Press.

Raymer, A.M., \& Berndt, R.S. (1996). Reading lexically without semantics: Evidence from patients with probable Alzheimer's disease. Journal of the International Neuropsychological Society, 2, 340-349.

Reicher, G.M. (1969). Perceptual recognition as a function of meaningfulness of stimulus material. Journal of Experimental Psychology, 81, 274-280. 
Reuter-Lorenz, P.A., \& Brunn, J.L. (1990). A prelexical basis for letter-by-letter reading: a case study. Cognitive Neuropsychology, 7, 1-20.

Riddoch, M.J., \& Humphreys, G.W. (1993). The Birmingham Object Recognition Battery (BORB). Hove, UK: Lawrence Erlbaum Associates Ltd.

Rumelhart, D.E., \& McClelland, J.L. (1982). An interactive activation model of context effects in letter perception: Part 2. The contextual enhancement effect and some tests and extensions of the model. Psychological Review, 89, 60-94.

Saffran, E.M., \& Coslett, H.B. (1996). “Attentional dyslexia” in Alzheimer's disease: A case study. Cognitive Neuropsychology, 13, 205-228.

Shallice, T. (1988). From neuropsychology to mental structure. Cambridge: Cambridge University Press.

Shallice, T., \& Warrington, E.K. (1977). The possible role of selective attention in acquired dyslexia. Neuropsychologia 15, 31-41.

Simmel, M.L., \& Goldschmidt, K.H. (1953). Prolonged posteclamptic aphasia. A.M.A Archives of Neurology and Psychiatry, 69, 80-83.

Strain, E., Patterson, K.E., \& Seidenberg, M.S. (1995). Semantic effects in single-word naming. Journal of Experimental Psychology: Learning, Memory and Cognition, 21, 1140-1154.

Thomsen, I.V., \& Harmsen, P. (1968). Retraining in a case of agnosic alexia. Folia Phoniatrica, $20,342-347$.

Warrington, E.K. (1991). Right neglect dyslexia: A single case study. Cognitive Neuropsychology, 8, 193-212.

Warrington, E.K., Cipolotti, L., \& McNeil, J. (1993). Attentional dyslexia-a single-case study. Neuropsychologia, 31, 871-885.

Warrington, E.K., \& Shallice, T. (1980). Word-form dyslexia. Brain, 103, 99-112.

Yamazaki, M., Ellis, A.W., Morrison, C.M., \& Lambon Ralph, M.A. (1997). Two age of acquisition effects in the reading of Japanese Kanji. British Journal of Psychology, 88, 407-421. 


\section{APPENDIX}

\section{AB's Real-word Errors to Word Targets in Reading} Aloud

\begin{tabular}{|c|c|c|c|c|c|}
\hline Target & Error & Target & Error & Target & Error \\
\hline act & at & cult & cut & job & hob \\
\hline advice & advance & cup & up & keeper & kipper \\
\hline agency & axe & debate & defence & keg & key \\
\hline ago & go & deed & Dean $(\times 2)$ & kitten & kitchen \\
\hline aim & Amy & defiance & defence & knee & keel \\
\hline aperture & appreciate & dell & deal & liar & lie \\
\hline arm & rum & dirty & dirt & lower & flower \\
\hline asbestos & aspidistras & dose & does & luck & lucky \\
\hline ass & asses & dough & done & $\mathrm{mac}$ & $\operatorname{man}$ \\
\hline ass & as & dread & dead & manner & manager \\
\hline assent & assist & dud & doll & mattress & Manchester \\
\hline banner & banana & due & dunk & mechanic & machine \\
\hline beam & bean & ease & easy & medicine & medical \\
\hline bed & Ben & eel & keel & merchant & medic \\
\hline beg & peg & envy & even & mercy & merry \\
\hline bib & Ben & era & egg & mister & mystery \\
\hline blade & black & eve & Elsie & monument & moment \\
\hline blister & blisters & ewe & few & moon & moron \\
\hline blood & blunder & few & feel & motor & trolley \\
\hline blunder & bluebird & fir & run & mug & mirror \\
\hline bog & $\operatorname{dog}$ & flow & flower & mum & medium \\
\hline bond & bound & fraud & friend & noun & moan \\
\hline boulder & boiled $(× 2)$ & frenzy & fire & nutrient & untreat \\
\hline boundary & embroidery & gain & gin & object & open \\
\hline break & breakfast & grade & grand & optimism & optimistic \\
\hline breast & east & graduate & grand & orb & order \\
\hline bring & bringing & groin & crown & origin & orange \\
\hline broader & bother & guise & guest & our & hurry \\
\hline broader & border & hammer & amber & outbreak & break \\
\hline burn & bury & hank & hanky & owe & owl \\
\hline canoe & can & harm & arm & own & owl $(\times 2)$ \\
\hline caste & castle & hey & hen & paintbrush & paint \\
\hline cellar & ceiling & hide & hip & palm & Paul \\
\hline ceremony & crematorium & hind & hand & par & bar \\
\hline chasm & chase & horror & honour & parry & party \\
\hline chief & shift & horse & horses & pat & bat \\
\hline clause & glasses & hosepipe & hospital & patience & patient \\
\hline clever & clean & hover & hoover & patio & potato \\
\hline click & cluck & howl & owl & per & beer \\
\hline coffin & coffee & immunity & immediately & picture & pictures \\
\hline composer & composition & incident & indecent & pipe & pie \\
\hline corpse & compost & infinity & interview & pit & pint \\
\hline crank & crack & jet & jelly & plot & pilot \\
\hline crumb & crumble & jig & jug & plug & pub \\
\hline
\end{tabular}




\section{LAMBON RALPH \& ELLIS}

\begin{tabular}{llllll} 
Target & Error & Target & Error & Target & Error \\
\hline prisoner & prison & signal & single & term & team \\
pup & pub & sleight & silent & thaw & thorn \\
pup & Philip & snail & small & thumb & the \\
quantity & quality & sock & shock & timid & timber \\
rake & rank & soften & softer & tomb & Tom \\
rap & rip & soot & Scott & trip & tip \\
republic & rebellion & spice & space & trough & trousers \\
review & revenue & spike & spin & truce & trust \\
rib & ribbon & spire & spirit & truth & the \\
rub & rubber & spite & spirit & trying & tiring \\
sane & Sam & stale & stable & vale & Val \\
scarce & cake & stanza & stanzas & veil & real \\
score & scone & steak & still & verb & view \\
scorn & corn & stew & stem & virtue & variety \\
scout & Scott & stingy & stringing & warn & warm \\
scribe & scribbles & stool & school & wealth & wealthy \\
seller & shell & straw & strand & weed & wheel \\
shaker & shaking & stride & string & whence & white \\
shave & shame & suave & slave $(\times 2)$ & wick & work \\
shed & shield & supper & slipper & wrath & weather \\
shore & shoe & sword & sworn & wrath & want \\
shovel & shower & sword & swan & wreck & wicked \\
shriek & sheikh & syringe & servant & wrest & west \\
sigh & sight & tape & tap & yore & York \\
\hline & & & & &
\end{tabular}

